\title{
A QUADRUPOLE MASS SPECTROMETER BASED GAS ANALYZER FOR POWER TRANSFORMER FAULT ASSESSMENT
}

\author{
Saleh M. Sbenaty \\ Department of Engineering Technology and Industrial Studies \\ Middle Tennessee State University
}

\begin{abstract}
This paper describes the feasibility of using a quadrupole mass spectrometer-based gas analyzer to predict malfunctions in high-voltage oil-filled power transformers using the analysis of dissolved gases in oil technique. A vacuum system for the quadrupole analyzer and the gas introduction system is designed and built for this purpose. A method for the extraction of the dissolved gases in oil is developed and the gas introduction system is described. The spectra of the thirteen gas species of interest are obtained and the sensitivity factors for each gas are calculated. The spectra of a standard gas mixture and the dissolved gases in oil from a faulty transformer oil specimen are obtained. The data reduction procedure is described and is used to reduce these spectra to the partial pressures of the 13 gas species. Finally, the concentration of each gas is calculated and methods for fault assessments are presented.
\end{abstract}

\section{INTRODUCTION}

Gas analysis is one of the best available techniques for transformer fault prediction and diagnosis. Scientists have found several decades ago that a loaded power transformer tends to evolve gases $^{1,2}$. These gases, the result of normal aging processes of the insulating materials, dissolve in the transformer's oil. The concentrations of these gases are usually small in normal operation and depend upon the solubility of each gas in oil and the transformer's type. When a fault or a combination of faults exists in a power transformer, however, the concentrations of the evolved gases are comparatively large ${ }^{3}$. It was also realized that the amount of evolved gases and gas species depend on the nature of the fault. For example, hydrogen $\left(\mathrm{H}_{2}\right)$ and acetylene $\left(\mathrm{C}_{2} \mathrm{H}_{2}\right)$ are the main gaseous constituents when arcing in oil occurs. Hot spots mostly evolve carbon oxides $\left(\mathrm{CO}_{2}+\mathrm{CO}\right)$ and light hydrocarbon gases. On the other hand, partial discharges (corona) produce hydrogen and other light hydrocarbon gases. In addition, slowly developing faults were found to produce decomposition gases ${ }^{4}$. By analyzing these dissolved gases, therefore, one can detect an incipient fault and reveal the operating condition of a power transformer before a costly and/or catastrophic accident occurs such as interruption of service and explosion.

\section{FAULT DIAGNOSTIC TECHNIQUES}

Several diagnostic methods using gas analysis can be used to predict faults in a power transformer ${ }^{5,6}$.

- The Dornenburg Ratio Method uses the following four gas ratios: methane/hydrogen $\left(\mathrm{CH}_{4} / \mathrm{H}_{2}\right)$, acetylene/ethylene $\left(\mathrm{C}_{2} \mathrm{H}_{2} / \mathrm{C}_{2} \mathrm{H}_{4}\right)$, ethane/acetylene $\left(\mathrm{C}_{2} \mathrm{H}_{6} / \mathrm{C}_{2} \mathrm{H}_{2}\right)$, and acetylene/methane $\left(\mathrm{C}_{2} \mathrm{H}_{2} / \mathrm{CH}_{4}\right)$. These ratios are calculated from the measured concentrations 
of the dissolved gases then compared with predetermined limits to diagnose arcing, hot spots, and partial discharges ${ }^{3,5}$.

- The Rogers Ratio Method uses the following four gas ratios: $\mathrm{CH}_{4} / \mathrm{H}_{2}, \mathrm{C}_{2} \mathrm{H}_{6} / \mathrm{CH}_{4}, \mathrm{C}_{2} \mathrm{H}_{4} / \mathrm{C}_{2} \mathrm{H}_{6}$, and $\mathrm{C}_{2} \mathrm{H}_{2} / \mathrm{C}_{2} \mathrm{H}_{4}$ and compares the values of theses ratios with preset limits. This method gives more detailed analysis and can determine the operating condition of a power transformer from twelve different suggested diagnoses ${ }^{7}$.

- The CIGRE Ratio Method uses the following four gas ratios: $\mathrm{C}_{2} \mathrm{H}_{2} / \mathrm{C}_{2} \mathrm{H}_{6}, \mathrm{H}_{2} / \mathrm{CH}_{4}$, $\mathrm{C}_{2} \mathrm{H}_{4} / \mathrm{C}_{2} \mathrm{H}_{6}$, and $\mathrm{C}_{2} \mathrm{H}_{4} / \mathrm{C}_{3} \mathrm{H}_{6}$ (ethylene/propylene) to determine the type of fault in ways similar to the Rogers method ${ }^{8}$.

- The Duval Method uses a trilinear representation of $\mathrm{CH}_{4}, \mathrm{C}_{2} \mathrm{H}_{2}$, and $\mathrm{C}_{2} \mathrm{H}_{4}$ to distinguish between various types of faults. Using these key gases, Duval was able to divide the triangular diagram into three main regions: partial discharge, arcing, and thermal degradation. He was also able to define two sub-regions for low energy arcing and for high energy arcing ${ }^{9}$.

- The Gas Nomograph Method, developed by Analytical Associates, provides a visual pattern that indicates the type of transformer's fault. A series of vertical logarithmic scales of key gases $\left(\mathrm{H}_{2}, \mathrm{CH}_{4}, \mathrm{C}_{2} \mathrm{H}_{2}, \mathrm{C}_{2} \mathrm{H}_{4}, \mathrm{C}_{2} \mathrm{H}_{6}, \mathrm{CO}\right.$, and $\left.\mathrm{CO}_{2}\right)$ are used in this case. The concentration of these gases are placed on the scales and lines are drawn between the values on adjacent scales. The positive or negative slopes of these lines identify the nature of the fault as indicated by the key at the bottom of the scale ${ }^{8}$.

The first two methods are recommended by the ANSI/IEEE guides ${ }^{5,6}$ and are the most widely used in the industry. It should be noted here, however, that several simultaneously occurring faults can cause ambiguity and the result may imply a "no fault" condition. In addition, an old fault that is no longer active may still provide data indicating a fault. Recently, several commercially available software packages that employ fuzzy logic and neural network implementations of the above methods are tailored for automatic dissolved gas analysis and fluid quality analysis ${ }^{8,10}$.

\section{GAS CONCENTRATION MEASURMENTS}

Several monitoring detectors can provide on-line measurements of four key gases ${ }^{11}\left(\mathrm{H}_{2}, \mathrm{C}_{2} \mathrm{H}_{2}\right.$, $\mathrm{C}_{2} \mathrm{H}_{4}$, and $\mathrm{CO}$ ), the total combustible gas ${ }^{12}$, or the hydrogen gas concentration ${ }^{13,14}$ are commercially available. Although these monitors are useful warning devices, they do not, however, provide a complete fault assessment.

For a complete gas analysis, therefore, the concentrations of at least thirteen gas species must be measured ${ }^{5,6}$. These are: hydrogen $\left(\mathrm{H}_{2}\right)$, methane $\left(\mathrm{CH}_{4}\right)$, acetylene $\left(\mathrm{C}_{2} \mathrm{H}_{2}\right)$, ethylene $\left(\mathrm{C}_{2} \mathrm{H}_{4}\right)$, ethane $\left(\mathrm{C}_{2} \mathrm{H}_{6}\right)$, propylene $\left(\mathrm{C}_{3} \mathrm{H}_{6}\right)$, propane $\left(\mathrm{C}_{3} \mathrm{H}_{8}\right)$, carbon monoxide $(\mathrm{CO})$, carbon dioxide $\left(\mathrm{CO}_{2}\right)$, oxygen $\left(\mathrm{O}_{2}\right)$, nitrogen $\left(\mathrm{N}_{2}\right)$, water $\left(\mathrm{H}_{2} \mathrm{O}\right)$, and argon $(\mathrm{Ar})$.

Since the concentrations of the evolved gases are normally small, parts per million, a very sensitive instrument must be used for a complete gas analysis. A gas chromatograph (GC) and/or a mass spectrometer (MS) are the recommended instruments by the ANSI/IEEE guides ${ }^{5,6}$. There are, however, several advantages of a mass spectrometer over a gas chromatograph when field operating conditions and automation requirements are considered. For example, a GC may require two gas carriers or two columns for a complete gas analysis; the temperature of the column, inlet port, and the detector must be precisely controlled; and calibration with one or 
more standard mixtures is required daily. Gas Chromatographs are, therefore, considered to be "laboratory" instruments. In fact, an automated transformer-oil gas analysis system (TOGA) has been developed for laboratory applications using a static headspace sampler and a capillary gas chromatograph $^{15}$.

With recent advancements in spectroscopy and vacuum systems, mass spectrometers have become increasingly compact, reliable, and sensitive ${ }^{16}$. They are now simpler to operate and maintain and can be easily automated ${ }^{17}$. They have recently gained wide recognition from the industry where they are used in process control and elemental analysis ${ }^{18}$.

\section{THE QUADRUPOLE MASS SPECTROMETER}

A mass spectrometer is an instrument that produces a stream of ions from the sample being analyzed, separates the ions into a spectrum according to their mass-to-charge ratios, and determines the relative abundance of each type of ion present ${ }^{19}$. Detection of impurities in the order of a few parts per trillion, in many applications, has made the mass spectrometer an essential tool in the industrial, environmental, medical, scientific, and law enforcement fields. Quadrupole mass spectrometer (QMS), in particular, has several advantages over other analyzers amongst which are the relative low cost, small size, lack of magnetic field, and the large mass and pressure ranges ${ }^{20}$.

This paper describes gas analysis procedure for power transformer fault prediction and diagnosis using a QMS. A vacuum system for the quadrupole analyzer and a gas introduction system were designed and built. A method for the extraction of the dissolved gases in oil was developed for this purpose. The spectra of the thirteen gas species of interest were obtained and the sensitivity factors for each gas were calculated. The spectra of a standard gas mixture and the dissolved gases in oil from a faulty transformer oil specimen were obtained. Finally, the concentration of each gas species was calculated and a method for fault assessment is presented.

\section{DISSOLVED GASES EXTRACTION SYSTEM}

The complete gas analyzer system using a QMS is shown in Figure 1. Oil samples used for gas analysis need to be drawn from the transformer without any atmospheric contact. A syringe or a pre-evacuated container should be used for this purpose $e^{5,6}$. The dissolved gases were extracted from the oil sample by introducing the oil into a pre-evacuated known volume as recommended by the ANSI/IEEE guides. The extractor is connected directly to the gas introduction system of the quadrupole analyzer which simplify sample preparation and reduces analysis time. This system is well suitable for automation since there is no need to compress the extracted gas sample and transfer it to the analyzer.

The volume of the extracted gas sample was corrected to the standard temperature and pressure (STP) using the gas equation:

$$
\mathrm{P}_{0} * \mathrm{~V}_{\mathrm{G} 0} / \mathrm{T}_{0}=\mathrm{P}_{\mathrm{R}} * \mathrm{~V}_{\mathrm{R}} / \mathrm{T}_{\mathrm{R}}
$$

where

$\mathrm{P}_{0} \quad$ is the standard pressure in Torr (1 atm or 760 Torr),

$\mathrm{V}_{\mathrm{G} 0}$ is the volume of the extracted gas sample at STP in ml, 
$\mathrm{T}_{0} \quad$ is the standard temperature $\left(0^{\circ} \mathrm{C}\right)$ in degree Kelvin or $273.16^{\circ} \mathrm{K}$,

$\mathrm{P}_{\mathrm{R}} \quad$ is the absolute pressure in the reservoir in Toor,

$\mathrm{T}_{\mathrm{R}} \quad$ is the ambient temperature $\left(25^{\circ} \mathrm{C}\right)$ in degree Kelvin or $298.16^{\circ} \mathrm{K}$, and

$\mathrm{V}_{\mathrm{R}} \quad$ is the volume of the total extraction space $(3375 \mathrm{ml})$ minus the volume of the oil sample $\left(\mathrm{V}_{\mathrm{S}}\right)$ in $\mathrm{ml}$.

Therefore

$$
\mathrm{V}_{\mathrm{G} 0}=1.205 \times 10^{-3} *\left(3375-\mathrm{V}_{\mathrm{S}}\right) * \mathrm{P}_{\mathrm{R}}
$$

The residual dissolved gases remained in the oil sample after extraction depend strongly on the partial pressure of each gas in the reservoir, the solubility of that gas in oil, and the temperature of the oil sample. In most cases, these residual gases can be ignored; however, they were considered here for added accuracy. The QMS was calibrated at a reservoir pressure of one Torr. The volume of the oil sample was, therefore, controlled until the pressure in the reservoir was just over or equal to one Torr.

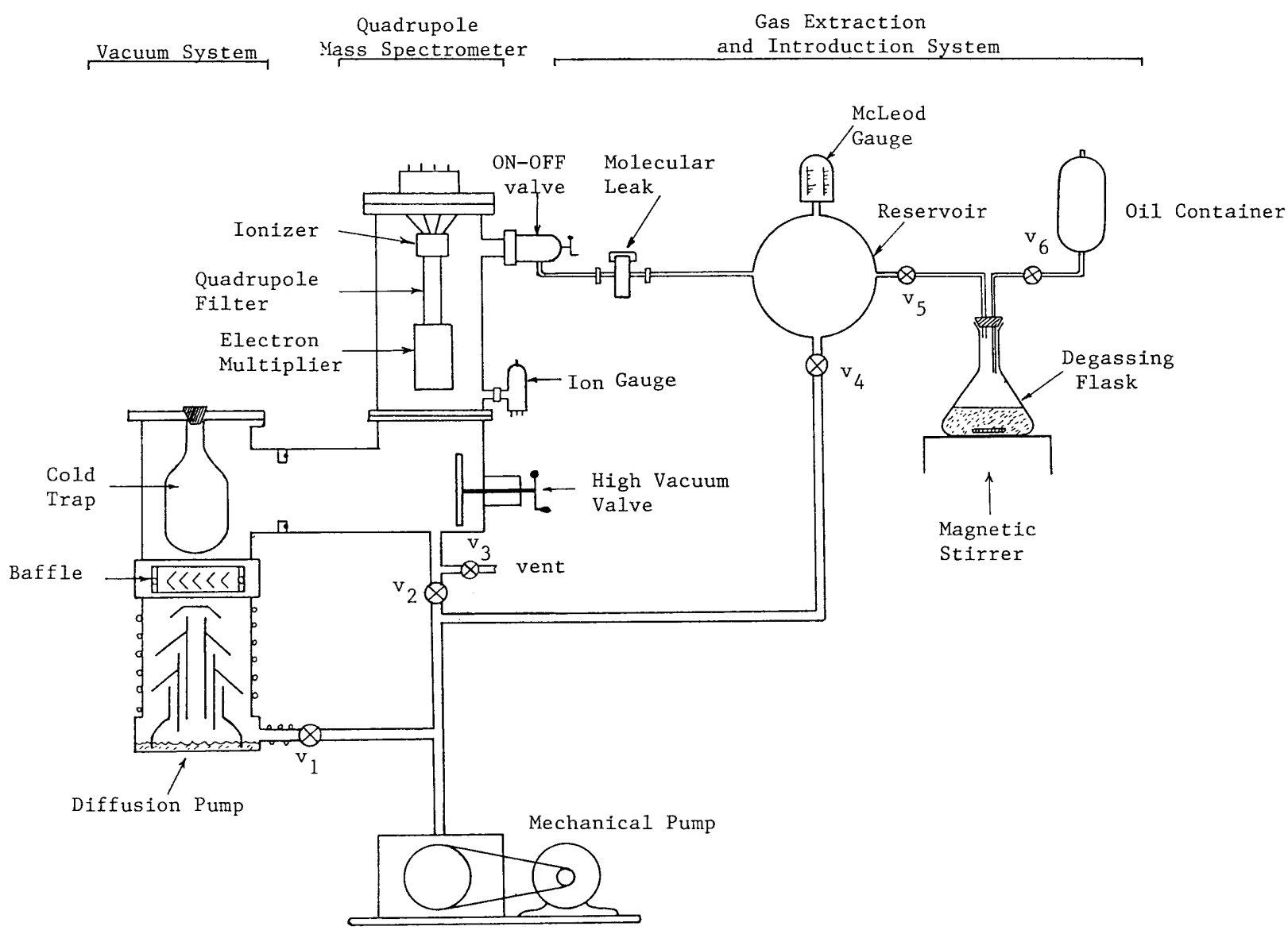

Figure 1. A Complete Gas Analyzer System for Transformer Fault Assessment Using a Quadrupole Mass Spectrometer 


\section{EXPERIMENTAL ARRANGMENT AND DATA AQUIZITION PROCEDURE}

An EAI Quadrupole Residual Gas Analyzer was used throughout the analysis (Fig. 1). A diffusion pump and a mechanical roughing pump were used to achieve, within an hour, a high vacuum of $1 \times 10^{-7}$ Torr or better. The high vacuum can be likewise achieved using a Turbo Molecular pump ${ }^{21}$. This pump is easier to automate and offers several advantages over a diffusion pump such as oil free and clean operation, rapid pumping, and no warm-up time. A pressure of much less than one mTorr can be reached in minutes and ultra high vacuum can be also achievable. The only significant disadvantage of a turbo molecular pump is that it costs is more than a comparable diffusion pump.

The test region base pressure was about $8 \times 10^{-8}$ Torr. In order to ignore the background spectrum, consequently, the test region operating pressure was chosen to be $1 \times 10^{-5}$ Torr. The reservoir volume was chosen to be $3375 \mathrm{ml}$ including the degassing flask. This volume should be large enough as compared with the oil sample that can be as much as $100 \mathrm{ml}$. The reservoir pressure was chosen to be 1 Torr so it can be maintained constant during at least one full scan.

The sensitivity factors of the QMS for each of the 13 gas species of interest $\left(\mathrm{h}_{\mathrm{i}}\right)$ was measured at all possible mass to charge $(\mathrm{M} / \mathrm{C})$ numbers by performing the following procedure:

1. The test region was evacuated to its base pressure (about $8 \times 10^{-8}$ Torr or less).

2. The reservoir was evacuated to its base pressure (about $1 \times 10^{-3}$ Torr or less).

3. The emission current was set to $0.5 \mathrm{~mA}$, electron energy to $80 \mathrm{eV}$, ion energy to $25 \mathrm{eV}$, focus voltage to $100 \mathrm{~V}$, and the electron extractor voltage to $40 \mathrm{~V}$.

4. The background spectrum was recorded before each run using an $x-y$ recorder.

5. The reservoir was filled with a pure gas at one atm, the pressure was then decreased to one Torr using the mechanical pump.

6. The pure gas was introduced to the test region and its spectra at the three different sensitivities of the $x-y$ recorder were obtained.

7. The current at each $\mathrm{M} / \mathrm{C}$ was calculated by subtracting the background spectrum from the spectrum of the pure gas.

8. The sensitivity factor $h_{i}$ at each $M / C$ was finally calculated from the following equation:

$$
\mathrm{h}_{\mathrm{i}}=\mathrm{H}_{\mathrm{i}} / \mathrm{P}
$$

where

$h_{i} \quad$ is the sensitivity factor at M/C number (i) expressed in Ampere/Torr,

$\mathrm{H}_{\mathrm{i}} \quad$ is the positive ion current at M/C number (i) in Amperes, and

$\mathrm{P} \quad$ is the test region pressure $\left(1 \times 10^{-5}\right.$ Torr $)$.

\section{MOLECULAR FRAGMANTATION PATTERN}

Ions are usually produced in the QMS ionizer by electron impact. Electrons emitted by a heated filament are accelerated toward an electron extractor using a positive potential. Interaction between the electron beam and the gas molecules results in an energy exchange and ionization. If the gas molecule absorbs an energy in the order of 10 to $20 \mathrm{eV}$, ionization of the parent molecule occurs and in many cases dissociation into fragment ions. At higher energy exchange (in the 
order of $70 \mathrm{eV}$ ), fragmentation of the sample molecule occurs and fragment ions are produced, in addition to the parent ion. These ions are then accelerated and focused before injection into the quadrupole analyzer. In the case of carbon dioxide molecule for example, ions of $\mathrm{M} / \mathrm{C}$ numbers corresponding to $\mathrm{CO}_{2}{ }^{+}, \mathrm{CO}^{+}, \mathrm{CO}_{2}{ }^{++}, \mathrm{O}^{+}$, and $\mathrm{C}^{+}$are formed with a reproducible pattern of relative abundance as shown in Figure 2. Different gas species produce different spectral patterns. Hydrocarbon gases produce a large variety of peaks ranging from nine for methane to twenty nine for propane. Peak overlapping in addition to the large number of peaks complicate data reduction procedure.

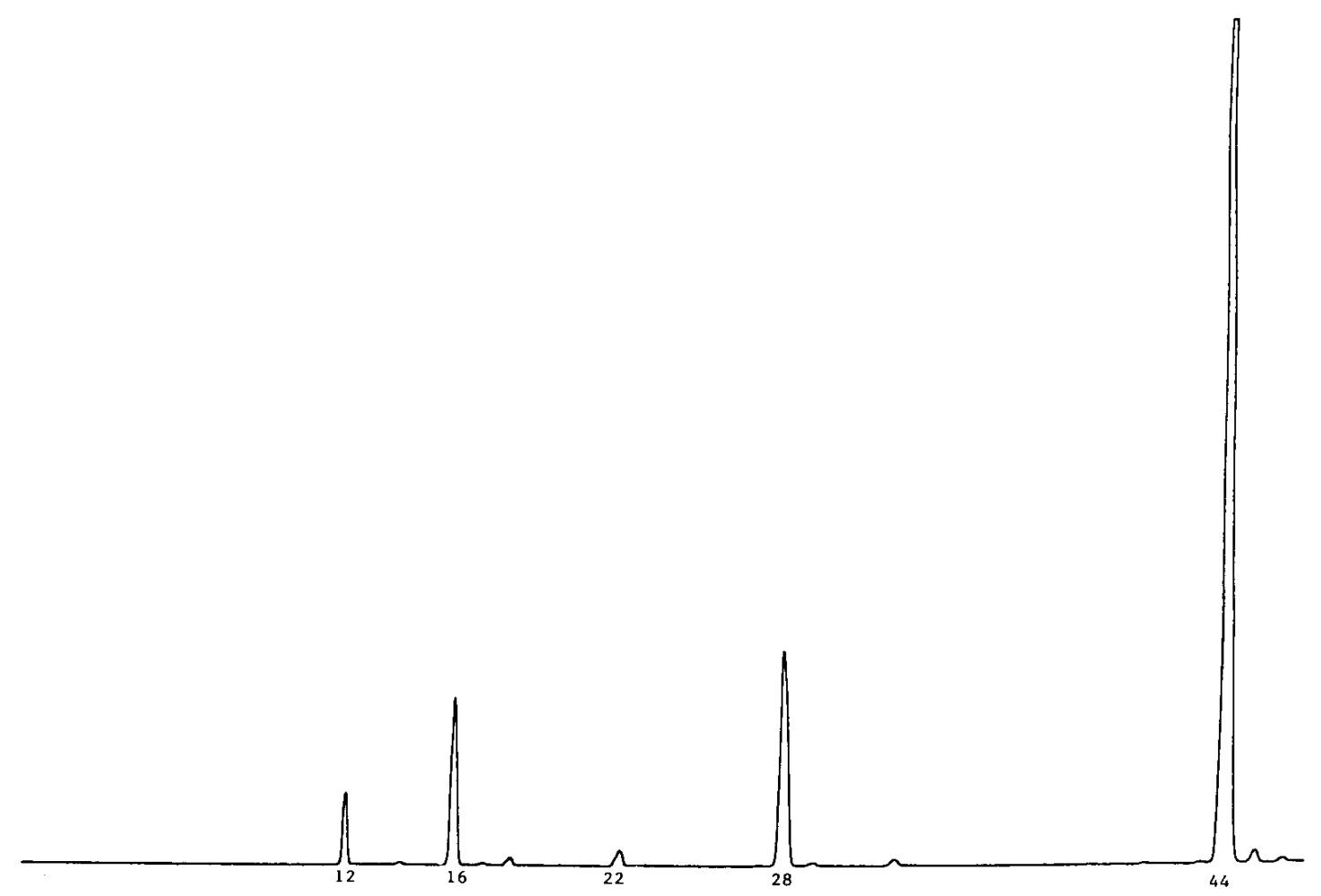

Figure 2. The Carbon Dioxide Spectrum.

The spectra of a standard mixture containing about $0.5 \% \mathrm{H}_{2}, 0.5 \% \mathrm{CH}_{4}, 0.5 \% \mathrm{C}_{2} \mathrm{H}_{4}, 0.5 \%$ $\mathrm{C}_{2} \mathrm{H}_{6}, 2 \% \mathrm{CO}, 4 \% \mathrm{CO}_{2}$, and $92 \% \mathrm{~N}_{2}$ were obtained at different sensitivities and are shown in Figure 3. This standard mixture was used for calibration and confirmation of data reduction procedure.

A dissolved gas sample extracted from an oil specimen of a faulty transformer provided by TVA were also analyzed and obtained at different sensitivities and are shown in Figure 4.

\section{PARTIAL PRESSURE MEASUREMNTS AND DATA REDUCTION PROCEDURE}

Partial pressure measurements using a mass spectrometer depend in large on the linear relationship between the positive ion current of a gas and its partial pressure in the ion source. This linearity can be expressed by: 


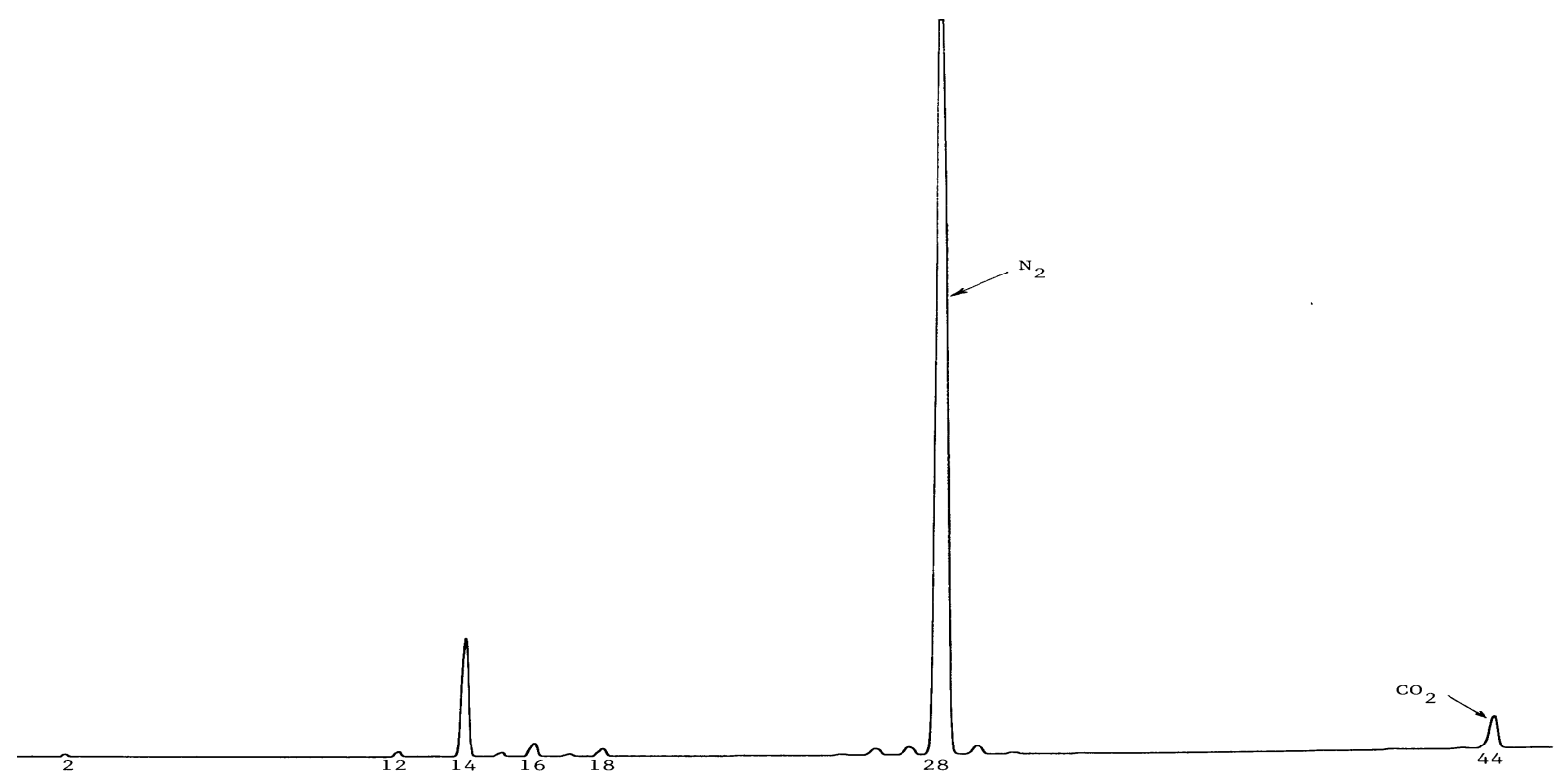

Figure 3. A. Standard Mixture Spectrum at a Sensitivity of $0.5 \mu \mathrm{A} / \mathrm{cm}$.

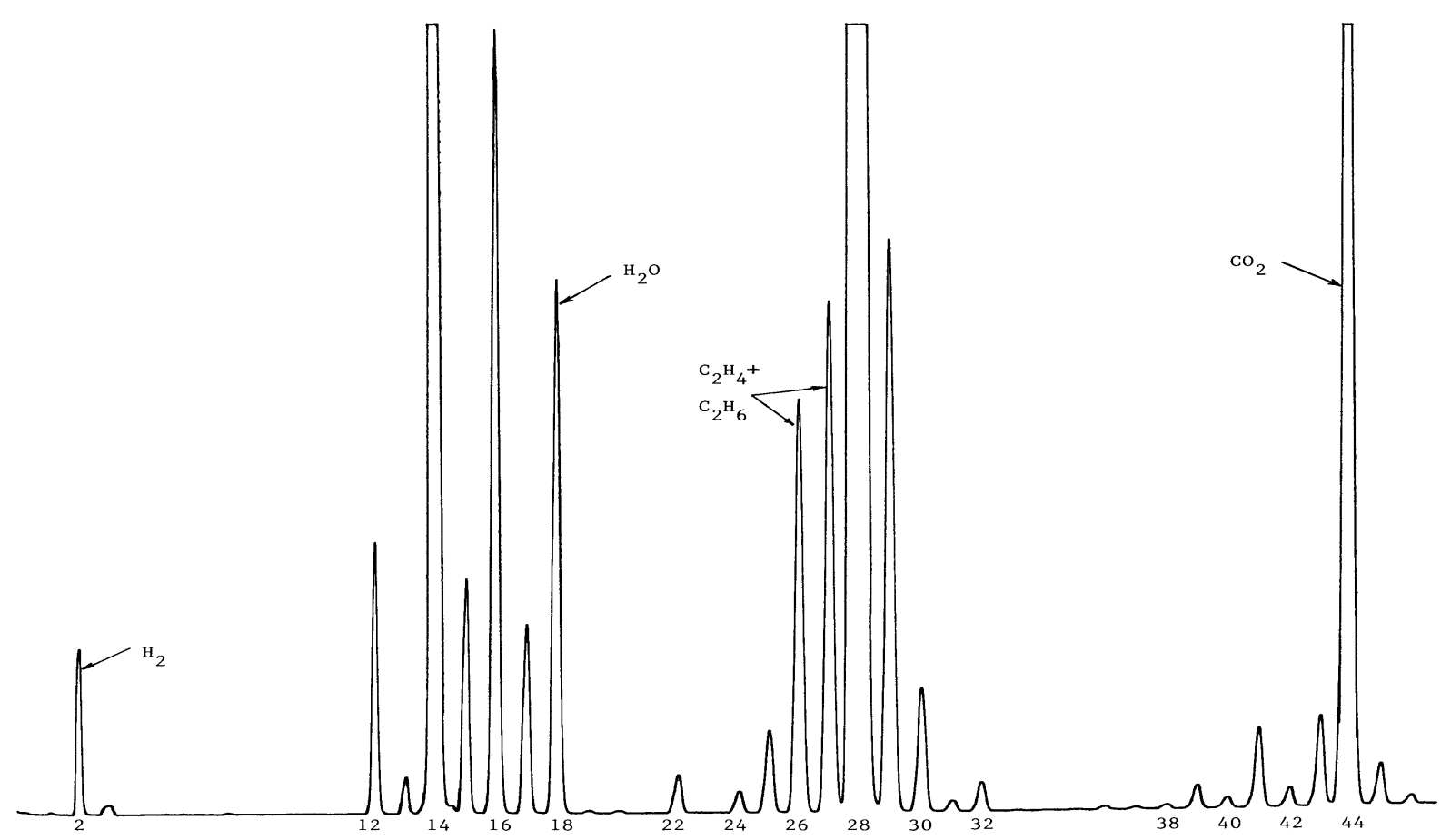

Figure 3. B. Standard Mixture Spectrum at a Sensitivity of $0.005 \mu \mathrm{A} / \mathrm{cm}$.

$$
\begin{aligned}
& \text { ॠ } \\
& N \\
& \omega \\
& \forall
\end{aligned}
$$




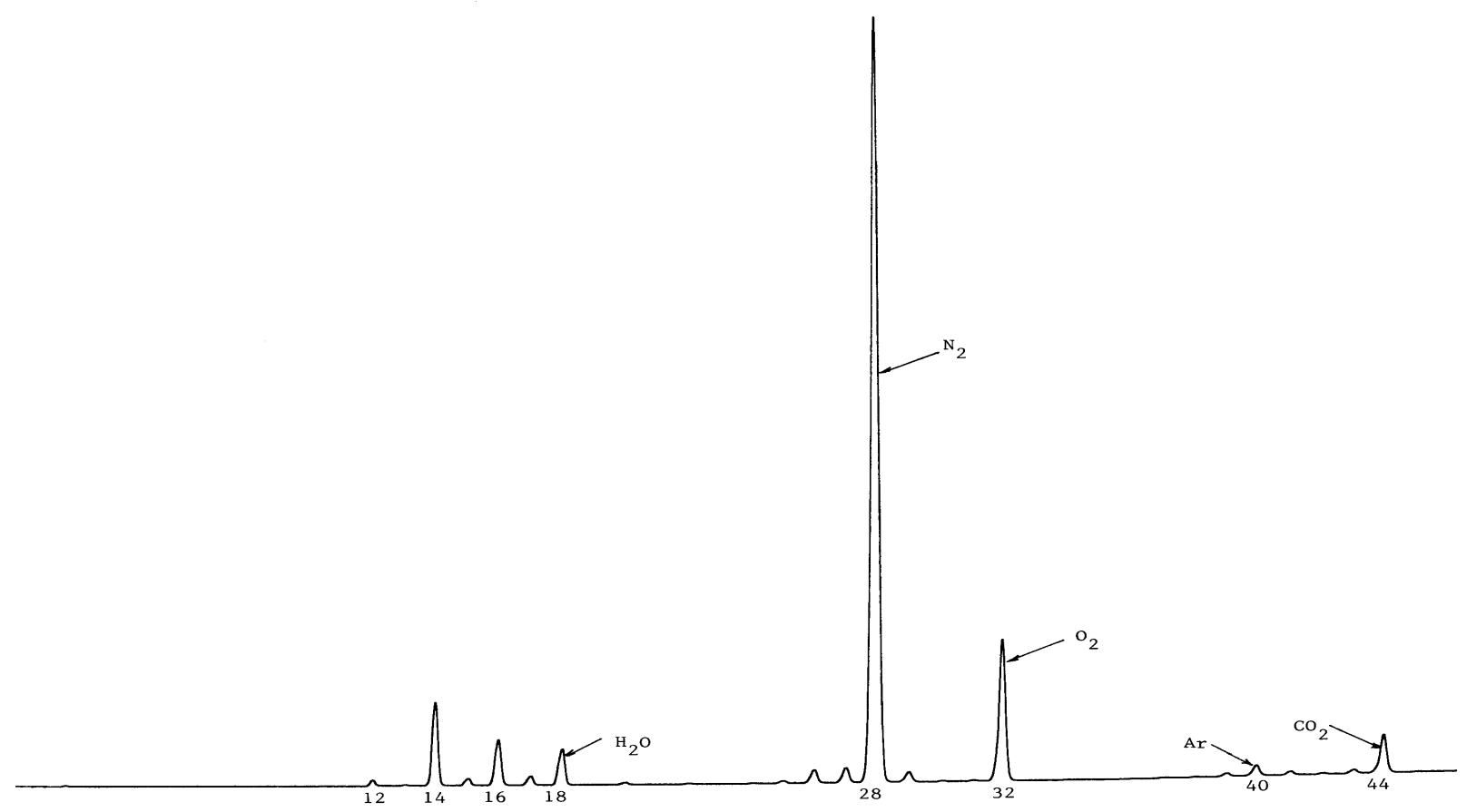

Figure 4. A. Extracted Gas Mixture Spectrum at a Sensitivity of $0.5 \mu \mathrm{A} / \mathrm{cm}$.

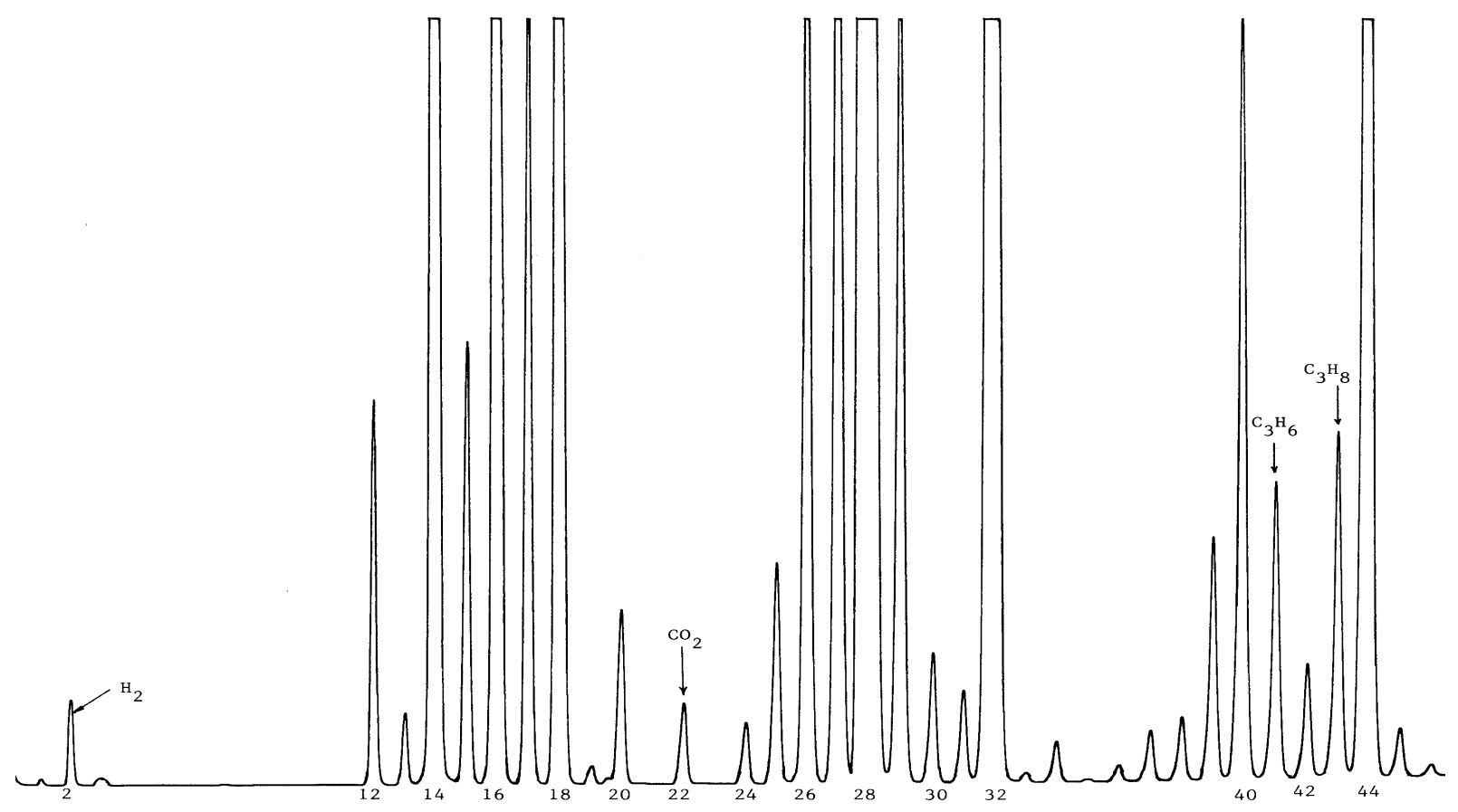

Figure 4. B. Extracted Gas Mixture Spectrum at a Sensitivity of $0.005 \mu \mathrm{A} / \mathrm{cm}$. 
where

$$
\mathrm{h}_{\mathrm{i}} * \mathrm{p}=\mathrm{H}_{\mathrm{i}} \quad 1 \leq \mathrm{i} \leq \mathrm{m}
$$

$\mathrm{h}_{\mathrm{i}} \quad$ is the sensitivity factor at M/C number (i) expressed in Ampere/Torr,

$\mathrm{p} \quad$ is the partial pressure of the pure gas in Torr,

$\mathrm{H}_{\mathrm{i}} \quad$ is the positive ion current at M/C number (i) in Amperes, and

$\mathrm{m} \quad$ is the largest $\mathrm{M} / \mathrm{C}$ number in the spectrum of the pure gas.

It should be noted here that the partial pressure of the pure gas, $p$, is equal to the absolute pressure of the test region, $\mathrm{P}$, when the background pressure is insignificant as compared with that of the pure gas. In this case, equation 3 and 4 become identical. Furthermore, the sensitivity factor, $h_{i}$, is a characteristic of the mass spectrometer and need to be determined for each pure gas at all possible $\mathrm{M} / \mathrm{C}$ numbers. The factor, $\mathrm{h}_{\mathrm{i}}$, depends on several parameters such as electron energy, ion energy, emission current, and electron multiplier voltage. These were set to their specified values mentioned above during each run.

If a mixture of $\mathrm{n}$ gas species is introduced into the analyzer, however, the resulting spectrum is a linear sum of the spectrum of each gas independent of the presence of other gases according to the following set of equations:

where

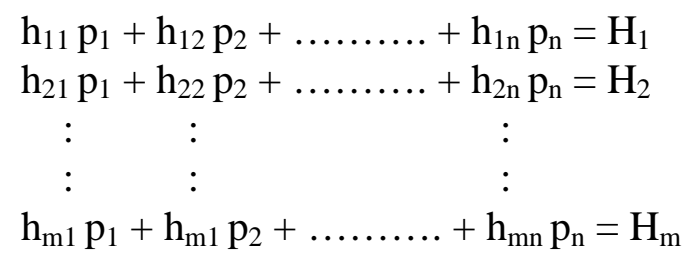

$\mathrm{m} \quad$ is the largest $\mathrm{M} / \mathrm{C}$ number in the mixture,

$\mathrm{n} \quad$ is the number of gas species in the mixture,

$\mathrm{h}_{\mathrm{ij}} \quad(1 \leq \mathrm{i} \leq \mathrm{m}$ and $1 \leq \mathrm{j} \leq \mathrm{n})$ is the sensitivity factor at $\mathrm{M} / \mathrm{C}$ number $\mathrm{i}$ and for gas $\mathrm{j}$ in Ampere/Torr,

$P_{j} \quad$ is the absolute partial pressure of gas $(j)$ in Toor, and

$\mathrm{H}_{\mathrm{i}} \quad$ is the total positive ion current at mass number I in Ampere.

In general, $\mathrm{n} \leq \mathrm{m}$, that is the number of peaks in the mixture spectrum is larger than the number of gas species due to the fragmentation of gas mixture molecules. For a successful analysis, therefore, the careful selection of $\mathrm{n}$ peaks is of great importance. The $\mathrm{n}$ equations resulted should include all $\mathrm{n}$ species of the gas mixture. Several factors should be considered here:

- Parent or major peaks are preferable for best detection of a trace amount of gas.

- Overlapped peaks should be avoided to reduce the effect of measurement errors.

- The relationship between $\mathrm{h}_{\mathrm{ij}}$ of different gas species at a specific M/C number.

The above set of equations can be expressed in matrix form as:

$$
[\mathrm{h}][\mathrm{p}]=[\mathrm{H}]
$$

In the first attempt, the partial pressure of each gas in the standard mixture was calculated from: 


$$
[\mathrm{p}]=[\mathrm{h}]^{-1}[\mathrm{H}]
$$

where $[\mathrm{h}]^{-1}$ is the inverse matrix of $[\mathrm{h}]$.

The above method produces unsatisfactory results because of the negative partial pressures of trace gases due to uncertainties in measurements. As a result, another computer program was written in order to solve the above set of equations by employing the method of substitution to repeatedly reduce the order of the equations until all 13 partial pressures were calculated. If the calculated partial pressure of a gas at any time is found to be negative, the partial pressure of that gas is set to zero. This eliminates the "domino" effect on other partial pressures. Additional peaks were also used to improve accuracy and the concentrations of the 13 gases were recalculated repeatedly until stable results were obtained ${ }^{22}$. The results from the data reduction program of the standard mixture spectrum is shown in Table 1.

Table 1. Actual and Measured Gas Concentrations of the Standard Mixture.

\begin{tabular}{ccc}
\hline Gas & Actual Concentration \% & Calculated Concentration \% \\
\hline $\mathrm{H}_{2}$ & 0.488 & 0.491 \\
$\mathrm{CH}_{4}$ & 0.496 & 0.482 \\
$\mathrm{C}_{2} \mathrm{H}_{4}$ & 0.529 & 0.543 \\
$\mathrm{C}_{2} \mathrm{H}_{6}$ & 0.494 & 0.495 \\
$\mathrm{CO}$ & 2.02 & 1.996 \\
$\mathrm{CO}_{2}$ & 3.99 & 3.926 \\
$\mathrm{~N}_{2}$ & 91.983 & 92.067 \\
\hline
\end{tabular}

The spectrum of the extracted gases from the transformer oil was also successfully reduced to the partial pressure of each gas using the data reduction program. The Rogers ratios were also calculated and the transformer was found to have arcing in oil. The results are shown in table 2.

Table 2. Measured Gas Concentrations and Gas Ratios From a Faulty Transformer Oil.

\begin{tabular}{rrrr}
\hline Gas & Concentration $(\mathrm{ppm})$ & $\mathrm{Gas}$ & Concentration (ppm) \\
\hline $\mathrm{H}_{2}$ & 137.7 & $\mathrm{CO}$ & 471.6 \\
$\mathrm{CH}_{4}$ & 129.4 & $\mathrm{CO}_{2}$ & 3226.6 \\
$\mathrm{C}_{2} \mathrm{H}_{2}$ & 86.3 & $\mathrm{H}_{2} \mathrm{O}$ & 3334.2 \\
$\mathrm{C}_{2} \mathrm{H}_{4}$ & 408.5 & $\mathrm{Ar}$ & 771.4 \\
$\mathrm{C}_{2} \mathrm{H}_{6}$ & 87.6 & $\mathrm{O}_{2}$ & 14088.6 \\
$\mathrm{C}_{3} \mathrm{H}_{6}$ & 108.4 & $\mathrm{~N}_{2}$ & 42981.7 \\
$\mathrm{C}_{3} \mathrm{H}_{8}$ & 1231.5 & $\mathrm{TCG}$ & 2661.0 \\
$\mathrm{CH}_{4} / \mathrm{H}_{2}=0.94$ & $\mathrm{C}_{2} \mathrm{H}_{6} / \mathrm{CH}_{4}=0.68$ & $\mathrm{C}_{2} \mathrm{H}_{4} / \mathrm{C}_{2} \mathrm{H}_{6}=4.66$ & $\mathrm{C}_{2} \mathrm{H}_{2} / \mathrm{C}_{2} \mathrm{H}_{4}=0.21$
\end{tabular}




\section{CONCLUSIONS}

Gas analysis for transformer fault diagnosis using a quadrupole mass spectrometer offers several advantages over other techniques. Some of which are high sensitivity, complete analysis, reliability, ease of operation, and most importantly, the possibility of a complete system automation for an on-line monitoring analyzer.

\section{ACKNOWLEDGMENTS}

The author wishes to express his sincere gratitude to the Dean of the Graduate School, Dr. Donald Curry, and to the Faculty Research Committee/Summer Research Program for the financial support and encouragement. The author is also grateful to Dr. Homer M. Powell for his help and technical support.

\section{REFERENCES}

1. T. Ishii and S. Namba, "Gas Evelotion from Transformer Insulating Materials Due to Aging Deterioration," Electrical Engineering in Japan, Vol. 90, No. 3, 1970, pp. 53-61.

2. H. Kinoshita et al., "Judgment of Electrical Insulation Deterioration by Gas Analysis Test on Oil Insulating Power Transformer,” Transactions IEE Journal, Vol. 94-B, 1974, pp. 65-72.

3. E. Dornenburg and O. E. Gerber, "Analysis of Dissolved and Free Gases for Monitoring Performance of OilFilled Transformers," The Brown Boveri Review, Vol. 54, No. 2/3 Feb./Mar. 1967, pp. 104-111.

4. C. Crawford and A. Wilson, "Incipient Transformer Fault Detected by Combustible Gas Monitoring Program and Ultra-Sound Tests," IEEE Trans. On Power Apparatus and Systems, Sep. 1964, pp. 926-930.

5. ANSI/IEEE Standards, "Guide for the Detection and Determination of Generated Gases in Oil-Immersed Transformers and Their Relation to the Serviceability of the Equipment," ANSI/IEEE Std. C 57. 104-1978, October 1978.

6. ANSI/IEEE Standards, "IEEE Guide for the Interpretation of Gases Generated in Oil-Immersed Transformers," ANSI/IEEE Std. C57. 104-1991, (ANSI) [1-55937-157-9].

7. R. R. Rogers, "IEEE and IEC Codes to Interpret Incipient Faults in Transformers, Using Gas in Oil Analysis," IEEE Trans. Elect. Insulation, Vol. EI-13, No. 5, Oct. 1978, pp. 349-353.

8. $\quad \partial \chi$ Delta-X Research, "Transformer Oil Analyst ${ }^{\mathrm{TM}}$, Automatic Dissolved-Gas Analysis, URL: http://www.hydracen.com/dx/toainfo/methods.htm, Sep. 20, 1996.

9. M. Duval, "Fault Gases Formed in Oil-Filled Breathing E.H.V. Power Transformers - The interpretation of Gas Analysis Data," IEEE PES Summer Meeting and Energy Resources Conf., Anaheim, California, July 14-19, 1974 C 74, pp. 476-478.

10. J. L. Kirtley Jr. et al, "Model-Based Monitoring of Transformers,” MIT Laboratory for Electromagnetic and Electronic Systems, URL: http://power.mit.edu/transformer/paper.html. Dec. 1996.

11. MICROMONITORS ${ }^{\circledR}$, “Tomorrow's Gas Sensor Technology - Today,” URL: http://www.micromonitors.com/tech.htm. Dec. 1996.

12. H.H. Wagner, "Five Years' Experience with Transformer Total Combustible Gas Fault detector Tests," IEEE Trans. on Power Apparatus and Systems, Aug. 1965, pp. 700-706.

13. G. Belanger and M. Duval, "Monitor for Hydrogen Dissolved in Transformer Oil," IEEE Trans. Electr. Insul, Vol. EI-12, No. 5, Oct. 197, pp. 334-339.

14. H. Tsukioka and k. Sugawara, "Study on Continuous Monitoring of Hydrogen Gas Dissolved in Transformer Oil,” Elect. Eng. in Japan, Vol. 100, No. 1, 1980, pp. 1-7.

15. J. Jalbert, R. Gilbert, and S. Brillante, "Early Diagnosis of Transformer Troubles - Automated dissolved- Gas Analysis of Transformer Oils," Peak Chemical Analysis, URL: http://www.dmo.hp.com/apg/peak296/transformer.html, Dec. 1996. 
16. M. G. Bevan and O. M. Uy, "Miniature Quadrupole Mass Spectrometer with Electron Multiplier,” URL:

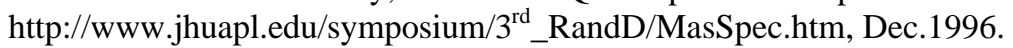

17. ESA, "Mass Spectrometer Expert System," Sensors and Measuring Techniques, URL: //esapub.esrin.esa.it.pointtotest/test133.html, Dec.1996.

18. C.D. Bartman, "Process Gas Analysis by Quadrupole MS" American Laboratory, Dec. 1985, pp. 57-63.

19. J. G. Webester, Medical Instrumentation, Applications and Design, $2^{\text {nd }}$ Edition, Houghton Miller Co., 1992.

20. M. A. Gruntman, "A Highly-Efficient Miniature Low-Power Neutral Gas Mass Spectrometer," University of South California, URL: http://cwis.usc.edu/dept...nts_Copyrights/2576w.htm, Dec. 1996.

21. G. L. Weissler and R. W. Carlson, Vacuum Physics and Technology, Academic Press, Inc. 1979.

22. S. M. Sbenaty and H. M. Powell, "A Mass Spectrometer Based Gas Analysis System for Power Transformer fault Diagnostics," Proceedings of the 30th Power Instrumentation Symposium sponsored by the Instrument Society of America, May 18-20, 1987, Rochester, N.Y., pp. 115-121.

\section{BIOGRAPHY}

DR. SALEH M. SBENATY is currently an Asst. Prof. in the Department of ET\&IS at MTSU. He received the B.S. degree in EE from Damascus University and the MS and Ph.D. degrees from Tennessee Tech. University. He is actively engaged in research in the area of mass spectrometry, power electronics, instrumentation, and lasers. He is a member of ASEE, IEEE, SME, and the honorary societies of Phi Kappa Phi, Eta Kappa Nu, and Tau Beta Pi. 